\title{
Interim analysis of a prospective randomized non-inferiority trial of cisplatin and fluorouracil induction chemotherapy with or without docetaxel in nasopharyngeal carcinoma
}

\author{
Ting Jin ${ }^{1,2, *}$, Wei-feng Qin ${ }^{1,2, *}$, Feng Jiang ${ }^{1,2}$, Qi-feng Jin ${ }^{1,2}$, Qi-chun Wei ${ }^{3}$, Xiu-wen \\ Tang ${ }^{4}$, Yong-shi Jia ${ }^{5}$, Xiao-nan Sun ${ }^{6}$, Wen-feng $\mathrm{Li}^{7}$, Xing-lai Feng ${ }^{1,2}$ and Xiao-zhong \\ Chen ${ }^{1,2}$ \\ ${ }^{1}$ Key Laboratory of Radiation Oncology in Zhejiang Province, Hangzhou, Zhejiang, People's Republic of China \\ ${ }^{2}$ Department of Radiation Oncology, Zhejiang Cancer Hospital, Hangzhou, Zhejiang, People's Republic of China \\ 3 Department of Radiation Oncology, Key Laboratory of Cancer Prevention and Intervention, China National Ministry of \\ Education, The SecondAffiliated Hospital, School of Medicine, Zhejiang University, Hangzhou, Zhejiang, People's Republic of \\ China \\ ${ }^{4}$ Department of Biochemistry and Genetics, Zhejiang University School of Medicine, Hangzhou, Zhejiang, People's Republic \\ of China \\ ${ }^{5}$ Department of Radiation Oncology, Zhejiang Provincial People's Hospital, Hangzhou, Zhejiang, People's Republic of China \\ ${ }^{6}$ Department of Radiation Oncology, Sir Run Run Shaw Hospital, College of Medicine, Zhejiang University, Hangzhou, \\ Zhejiang, People's Republic of China \\ 7 Department of Chemoradiation Oncology, The First Affiliated Hospital of Wenzhou Medical University, Wenzhou, Zhejiang, \\ People's Republic of China \\ * These authors have contributed equally to this study
}

Correspondence to: Xiao-zhong Chen, email: chenxiaozhongfy@163.com

Keywords: nasopharyngeal carcinoma, chemotherapy, concurrent chemoradiation, radiotherapy, docetaxel

Received: May 18, 2016

Accepted: June 15, 2016

Published: July 28, 2016

\section{ABSTRACT}

In this study, we aim to compare the progression-free survival (PFS) rates and side effects of induction chemotherapy based on docetaxel, cisplatin and fluorouracil (TPF) versus cisplatin and fluorouracil (PF) in patients with locoregionally-advanced nasopharyngeal carcinoma who received subsequent chemoradiotherapy. We randomly assigned 276 patients with stage III or IV NPC (without distant metastases) to receive either TPF or PF induction chemotherapy, followed by cisplatin-based chemoradiotherapy every 3 weeks and intensity-modulated radiation therapy for 5 days per week. After a minimum of 2 years follow-up, a PFS benefit was observed for TPF compared to PF, though this difference was not statistically significant $(84.5 \%$ vs. $77.9 \%, P=0.380$ ). Due to increased frequencies of grade 3 or 4 neutropenia and diarrhea, significantly more patients in the TPF group required treatment delays and dose modifications. Our findings suggest that PF induction chemotherapy has substantially better tolerance and compliance rates than TPF induction chemotherapy. However, the treatment efficacy of PF is not superior to TPF induction chemotherapy in patients with locoregionally-advanced NPC (ClinicalTrials.gov number, NCT01536223).

\section{INTRODUCTION}

Treatment outcomes for locoregionally-advanced nasopharyngeal cancer (NPC) remain unsatisfactory, with 5 -year overall survival (OS) rates of $53-80 \%$ and $28-61 \%$ for stage III and IV NPC, respectively [1-8].
Numerous studies have explored neoadjuvant, concurrent and adjuvant chemotherapy. Clinical trials $[9,10]$, meta-analyses [11, 12] and a systematic review [13] demonstrated concurrent chemoradiotherapy (CCRT) is most efficacious; concurrent cisplatin-based CCRT is now the standard of care for stage II-IVb NPC [13]. 
An induction-concurrent sequence may further improve treatment efficacy: NPC is chemosensitive and usually has a high objective response rate; early use of full doses of a potent combination of cytotoxic drugs may eradicate micrometastases more effectively; reducing tumor and cervical lymph node volumes may facilitate radiotherapy, which is particularly important in patients with extensive cranial involvement; and treatment-naive patients tolerate induction-concurrent sequences better than adjuvant chemotherapy [14-17]. Current NCCN guidelines recommend neoadjuvant chemotherapy (NACT) with CCRT as an option. A recent meta-analysis [18] demonstrated NACT provided an absolute 3-year OS gain of $5.13 \%$ and significantly reduced distant metastasis.

NACT based on docetaxel with cisplatin and 5-fluorouracil (TPF) provided a significant survival benefit in locally-advanced squamous cell carcinoma of the head and neck (SCCHN) compared to cisplatin-fluorouracil (PF) before either definitive radiotherapy (TAX323 trial) or carboplatin-based CCRT (TAX324 trial) [19,20]. However, in contrast to other head and neck squamous cell carcinomas, NPC is more chemosensitive and radiosensitive and has a proven association with EpsteinBarr virus. Moreover, it remains unknown whether TPF induction chemotherapy significantly prolongs survival compared to PF induction chemotherapy in patients with locoregionally-advanced NPC receiving CCRT. Therefore, we undertook a multi-center, open-label, randomized, noninferiority trial to compare PFS, tolerance and compliance to TPF + CCRT versus PF + CCRT in Chinese patients with locoregionally-advanced NPC.

\section{MATERIALS AND METHODS}

\section{Patients}

Zhejiang Cancer Hospital Institutional Review Board for Medical Ethics approved this trial, which was performed in accordance with the Declaration of Helsinki; all patients provided written informed consent.

Staging was conducted according to the 2009 American Joint Committee on Cancer (AJCC) staging system. Enrollment criteria were pathologically-confirmed non-metastatic, histologically-proven non-keratinizing stage III or IV NPC without distant metastasis, in addition to Karnofsky performance score $\geq 70$; age 18 -70 years; adequate bone marrow (hemoglobin $\geq 80 \mathrm{~g} / \mathrm{L}$; white blood cells $\geq 4.0 \times 10^{9} / \mathrm{L} ;$ absolute neutrophil count $\geq 2.0$ $\times 10^{9} / \mathrm{L}$, platelets $\geq 100 \times 10^{9} / \mathrm{L}$ ), renal function (creatinine clearance $>60 \mathrm{ml} / \mathrm{min}$ ) and hepatic function (aspartate aminotransferase/alanine aminotransferase $\leq 1.5 \times$ upper limits of normal). Patients who previously received radiotherapy or chemotherapy, or had other cancers, cardiac arrhythmia, coronary heart disease, peripheral neuropathy, or had psychiatric disorders/psychological conditions that may adversely affect treatment compliance were excluded. Pregnant or lactating females and females of childbearing age who lacked effective contraception were also excluded.

\section{Radiotherapy}

Nasopharyngeal and neck target volumes were irradiated using intensity modulated radiation therapy (IMRT). Gross tumor volume (GTV) was based on tumor extent delineated by imaging and endoscopic findings at presentation. Clinical target volume (CTV) included the entire nasopharyngeal cavity, anterior third of clivus, pterygoid plates, parapharyngeal space, inferior sphenoid sinus, posterior third of nasal cavity and maxillary sinus, and drainage of the upper neck (levels II, III and Va) in $\mathrm{N} 0$ disease, and levels IV and $\mathrm{Vb}$ in N1-N3 disease. A total dose of 69-70.4 Gy in 30-32 fractions over 6 weeks was prescribed to the planning target volume of primary tumor (PTVg; GTV with 0.3-0.5 cm margin). A total dose of 63-67.2 Gy in 30-32 fractions over 6 weeks was prescribed to the planning target volume of metastatic nodes (PTVnd; GTVnd with 0.3-0.5 cm margin). PTV1 (high-risk clinical target volume; CTV with 0.3-0.5 cm margin) was prescribed 60-60.8 Gy over 30-32 fractions. PTV2 (low-risk clinical target volume) was prescribed 54-54.4 Gy over 30-32 fractions. External radiotherapy was administered once daily, 5 days/week. Tumor dose variation within tumor volume was $\pm 5 \%$.

\section{Chemotherapy}

For TPF, docetaxel $\left(75 \mathrm{mg} / \mathrm{m}^{2}\right)$ was administered as $1 \mathrm{~h}$ intravenous infusion, followed by intravenous cisplatin $\left(75 \mathrm{mg} / \mathrm{m}^{2}\right)$ over 0.5 to $3 \mathrm{~h}$, then 5 -fluorouracil $\left(600 \mathrm{mg} / \mathrm{m}^{2} /\right.$ day) as continuous $24 \mathrm{~h}$ infusion for 4 days. The PF group received intravenous cisplatin $\left(100 \mathrm{mg} / \mathrm{m}^{2}\right)$, followed by 5 -fluorouracil ( $800 \mathrm{mg} / \mathrm{m}^{2} /$ day) as continuous infusion for 5 days. Induction chemotherapy was administered every 3 weeks for three cycles, unless disease progression, unacceptable toxic effects or withdrawal of patient consent occurred. During CCRT, intravenous $80 \mathrm{mg} / \mathrm{m}^{2}$ cisplatin was administered every 3 weeks on day $1 \sim 60$ min prior to radiation.

Dose modifications during NACT were based on preceding cycle nadir blood counts and interim toxicities. For TPF, docetaxel was reduced to $60 \mathrm{mg} / \mathrm{m}^{2}$ if absolute platelet count was $<25000$ cells $/ \mu \mathrm{L}$ or absolute neutrophil count was $<500$ cells $/ \mu \mathrm{L}$. Cisplatin was decreased to 60 $\mathrm{mg} / \mathrm{m}^{2}$ in the third course if absolute platelet count was $<25000$ cells $/ \mu \mathrm{L}$ or absolute neutrophil count was $<500$ cells $/ \mu \mathrm{L}$ after docetaxel dose modifications. Fluorouracil was reduced by $120 \mathrm{mg} / \mathrm{m}^{2}$ for grade 3 mucositis or diarrhea, and chemotherapy stopped permanently if 
grade 4 toxic effects developed. For PF, cisplatin was decreased to $80 \mathrm{mg} / \mathrm{m}^{2}$ if absolute platelet count was < 25000 cells $/ \mu \mathrm{L}$ or absolute neutrophil count was $<500$ cells $/ \mu \mathrm{L}$. Fluorouracil was decreased by $160 \mathrm{mg} / \mathrm{m}^{2}$ for grade 3 mucositis or diarrhea, and chemotherapy stopped permanently if grade 4 toxic effects developed.

\section{Follow-up}

All patients underwent complete physical examinations including full blood count and comprehensive serum chemistry profiling after each cycle of NACT. At the end of NACT and radiotherapy, a followup MRI was conducted to evaluate tumor response. After all therapy, comprehensive scans, including chest CT and ultrasonography or intensive CT of the abdomen, were performed in addition to MRI. Treatment-related toxicities were graded using Common Toxicity Criteria Version 3.0 [21]. Primary follow-up method was outpatient appointments. Clinical examinations, full blood count, comprehensive serum chemistry profiling, MRI and intensive CT, and abdominal ultra-sonography or nasopharyngoscopy were performed every 3 months in first two years and every 6 months thereafter. Bone scans were performed for suspected bone metastases; other tests were conducted at the discretion of physicians.

\section{Study design and statistical methods}

Prospective, randomized, non-inferiority trial; PFS was the primary endpoint; adverse events, local control and overall survival were secondary endpoints.

We hypothesized 3-year PFS would be $80 \%$ for both arms; therefore, a sample size of 252 for each group would achieve an $80 \%$ power to detect a marginal non-inferiority difference between groups (allowing for 10\% reduction in sample size). The study arm proportion was assumed to be $70 \%$ under the null hypothesis of inferiority; power was computed for an actual study arm proportion of $80 \%$ using the one-sided $z$-test (unpooled) at a significance level of .025. Interim analysis to assess whether PFS was significantly different between arms was scheduled when the first group of 252 patients had completed treatment and been followed-up for $>24$ months.

Survival curves were constructed using the Kaplan-Meier method and compared using the log-rank test. Pretreatment characteristics were compared using Pearson's chi-square and independent sample $t$-tests. A Cox regression model was employed for multivariate analysis. All $P$-values were two-tailed and considered statistically significant if $P<0.05$. Statistical analyses were performed using SPSS 19 for Windows (SPSS, Chicago, IL, USA).

\section{RESULTS}

\section{Patients}

Between April 1, 2012 and April 1, 2014, 276 patients treated at six centers in China were enrolled. The cutoff date for interim analysis of PFS was April 1, 2016 (2 years follow-up for last patient enrolled; median, 36 months; range, 24-48 months). The groups of patients randomly allocated to receive TPF and PF were well-balanced in terms of baseline demographic and clinicopathological characteristics and radiotherapy techniques (Table 1).

\section{Treatment and dose modifications}

All 276 patients $(100 \%)$ started induction chemotherapy (Table 2). In the TPF group, docetaxel was decreased to $60 \mathrm{mg} / \mathrm{m}^{2}$ in the second course for 60 patients because of grade 4 neutropenia and/or thrombocytopenia, cisplatin decreased to $60 \mathrm{mg} / \mathrm{m}^{2}$ in the third course for 7 patients due to grade 4 neutropenia and/or thrombocytopenia after docetaxel, and fluorouracil decreased by $120 \mathrm{mg} / \mathrm{m} 2$ for 11 patients due to grade 3 mucositis or diarrhea. In the PF group, cisplatin was decreased to $80 \mathrm{mg} / \mathrm{m} 2$ for 21 patients because of grade 4 neutropenia and/or thrombocytopenia and fluorouracil decreased by $160 \mathrm{mg} / \mathrm{m} 2$ for 8 patients because of grade 3 mucositis or diarrhea.

\section{Efficacy}

Overall, 3-year PFS and OS were 81.1\% and 91.1\%, respectively (Figure 1A-1B). Median PFS was 34.5 months for both the TPF group and PF group. Estimated 3 -year PFS was $84.5 \%$ for the TPF group and $77.9 \%$ for the PF group ( $P=0.380$; Figure $1 \mathrm{C})$. Median survival was 36 months for the TPF group and 35 months for the PF group; estimated 3-year OS was $91.1 \%$ in the TPF group and $91.1 \%$ in the PF group ( $P=0.821$; Figure 1D). Overall, $31 / 276$ patients $(11.2 \%)$ died: $15 / 138(10.7 \%)$ in the TPF group and 16/138 (11.6\%) in the PF group. Tumor progression was the most common cause of death (11.6\% of TPF group and $10.7 \%$ of PF group). TPF was not associated with improved survival in any subgroup, including patients with advanced nodal category or primary tumor stage (Table 3). By last analysis, 26/138 $(18.8 \%)$ patients in the TPF group and $32 / 138(23.2 \%)$ in the PF group ( $P=0.375$; Table 3$)$ had suffered treatment failure. 10 patients in the TPF group developed local recurrence and 4 patients developed regional recurrence; 16 patients in the PF group developed local recurrence 
Table 1: Baseline characteristics of the 276 patients with locoregionally-advanced nasopharyngeal cancer in each treatment arm

\begin{tabular}{|l|l|l|l|}
\hline Variable & $\begin{array}{l}\text { TPF +CCRT } \\
(\boldsymbol{n}=\mathbf{1 3 8})\end{array}$ & $\begin{array}{l}\text { PF + CCRT } \\
(\boldsymbol{n}=\mathbf{1 3 8})\end{array}$ & P-value* \\
\hline Sex & $99(71.7)$ & & 0.894 \\
\hline Male & $39(28.3)$ & $98(71.0)$ & \\
\hline Female & & $40(29.0)$ & \\
\hline Age, years & 48 & & \\
\hline Median & $18-68$ & 50 & \\
\hline Range & & $25-69$ & 0.626 \\
\hline Karnofsky performance score & $130(94.2)$ & & \\
\hline 100-90 & $8(5.8)$ & $128(92.6)$ & \\
\hline $80-70$ & & $10(7.4)$ & 0.544 \\
\hline T category & $25(18.1)$ & & \\
\hline T 1-2 & $113(81.9)$ & $29(21)$ & \\
\hline T 3-4 & & $109(79)$ & 0.801 \\
\hline N category & $48(34.8)$ & & \\
\hline N 0-1 & $90(65.2)$ & $50(36.2)$ & \\
\hline N 2-3 & & $88(63.8)$ & \\
\hline Stage & $86(62.3)$ & & \\
\hline III & $52(37.7)$ & $94(68.1)$ & \\
\hline IVA-B & & $44(31.9)$ & \\
\hline
\end{tabular}

* calculated using the $\chi^{2}$ test. Values are shown as $n(\%)$ unless indicated otherwise

Table 2: Dose modifications and treatment delays during induction chemotherapy

\begin{tabular}{|l|l|l|l|}
\hline & TPF $(\boldsymbol{n}=\mathbf{1 3 8})$ & PF $(\boldsymbol{n}=\mathbf{1 3 8})$ & $\boldsymbol{P}$-value* \\
\hline Dose modifications during induction chemotherapy & & & \\
\hline Docetaxel & $60(43.5)$ & - & \\
\hline Cisplatin & $7(5.1)$ & $21(15.2)$ & 0.005 \\
\hline Fluorouracil & $11(8.0)$ & $8(5.8)$ & 0.476 \\
\hline Treatment delays during induction chemotherapy & & & \\
\hline Patients who experienced delays, $n(\%)$ & $46(33.3)$ & $25(18.1)$ & 0.004 \\
\hline Reason for delay & & & \\
\hline Hematologic & $26(18.8)$ & $13(9.4)$ & 0.025 \\
\hline Non-hematologic & $10(7.2)$ & $3(2.2)$ & 0.047 \\
\hline Other** & $10(7.2)$ & $9(6.5)$ & 0.812 \\
\hline
\end{tabular}

* Calculated using the $\chi^{2}$ test.

** including personal reasons and vacations.

and 4 patients developed regional recurrence. In the TPF group, 10 patients developed distant metastases and 2 patients developed both distant metastases and locoregional recurrence. In the PF group, 9 patients developed distant metastases and 3 patients developed both distant metastases and locoregional recurrence.

\section{Adverse events}

The frequencies of grade 3 or 4 anemia and thrombocytopenia and grade 1 or 2 liver dysfunction were similar between groups. Grade 3 or 4 neutropenia occurred in $63.8 \%$ of the TPF group and $28.3 \%$ of the PF group $(P$
$<0.001)$ and grade 3 or 4 febrile neutropenia in $10.1 \%$ of the TPF group and $2.9 \%$ of the PF group $(P=0.015$; Table $4)$. Grade 1 or 2 kidney dysfunction occurred in $2.2 \%$ of the TPF group and $8.0 \%$ of the PF group $(P=0.028$; Table $4)$. Except for a non-significant trend towards increased vomiting in the PF group, there were no major differences in non-hematologic adverse events between groups during induction chemotherapy (Table 4). More patients in the TPF group experienced treatment delays compared to the PF group (33.3\% vs. $18.1 \%, P=0.004$; Table 2 ); grade 3 or 4 hematologic adverse events mainly accounted for this difference and were responsible for treatment-associated delays in $18.8 \%$ of patients in the TPF group and $9.4 \%$ of the PF group $(P=0.025$; Table 2$)$. 
Table 3: Comparison of the antitumor efficacy of the induction chemotherapy regimens

\begin{tabular}{|c|c|c|c|c|}
\hline Variable & $\begin{array}{l}\text { TPF+CCRT } \\
(n=138)\end{array}$ & $\begin{array}{l}\mathrm{PF}+\mathrm{CCRT} \\
(n=138)\end{array}$ & $\begin{array}{l}\text { Hazard Ratio } \\
(95 \% \text { CI })\end{array}$ & $P$-value* \\
\hline Progression-free survival & & & $0.455-1.350$ & 0.380 \\
\hline Median duration, months & 34.5 & 34.5 & & \\
\hline \multicolumn{5}{|l|}{ Rate, $\%$} \\
\hline Two-year & 86.2 & 86.9 & & \\
\hline Three-year (estimated) & 84.5 & 77.9 & & \\
\hline \multicolumn{5}{|c|}{$\begin{array}{l}\text { Median duration according to disease stage, } \\
\text { months }\end{array}$} \\
\hline Stage III & 34.5 & 34 & $0.469-2.098$ & 0.984 \\
\hline Stage IV & 34.5 & 35 & $0.294-1.429$ & 0.282 \\
\hline \multicolumn{5}{|c|}{$\begin{array}{l}\text { Median duration according to primary tumor } \\
\text { category, months }\end{array}$} \\
\hline T1-2 & 32 & 36 & $0.642-8.084$ & 0.203 \\
\hline T3-4 & 35 & 34 & $0.347-1.168$ & 0.145 \\
\hline \multicolumn{5}{|c|}{$\begin{array}{l}\text { Median duration according to nodal category, } \\
\text { months }\end{array}$} \\
\hline N0-1 & 34.5 & 34.5 & $0.358-2.948$ & 0.960 \\
\hline $\mathrm{N} 2-3$ & 34.5 & 34.5 & $0.379-1.351$ & 0.302 \\
\hline \multicolumn{5}{|l|}{ Overall survival } \\
\hline Median duration, months & 36 & 35 & $0.455-1.866$ & 0.821 \\
\hline \multicolumn{5}{|l|}{ Rate, $\%$} \\
\hline At 2 years & 95.7 & 93.9 & & \\
\hline At 3 years & 91.1 & 91.1 & & \\
\hline \multicolumn{5}{|c|}{$\begin{array}{l}\text { Median duration according to disease stage, } \\
\text { months }\end{array}$} \\
\hline III & 36 & 37 & $0.407-3.634$ & 0.726 \\
\hline IV & 35.5 & 35.5 & $0.303-1.960$ & 0.584 \\
\hline \multicolumn{5}{|c|}{$\begin{array}{l}\text { Median duration according to primary tumor } \\
\text { category, months }\end{array}$} \\
\hline $\mathrm{T} 1-2$ & 37 & 38 & $0-3.951 \mathrm{E}+228$ & 0.962 \\
\hline $\mathrm{T} 3-4$ & 35 & 34 & $0.342-1.527$ & 0.394 \\
\hline \multicolumn{5}{|c|}{$\begin{array}{l}\text { Median duration according to nodal category, } \\
\text { months }\end{array}$} \\
\hline N0-1 & 36 & 35 & $0.247-2.662$ & 0.730 \\
\hline $\mathrm{N} 2-3$ & 36 & 35 & $0.411-2.383$ & 0.981 \\
\hline \multicolumn{5}{|l|}{ Sites of treatment failure } \\
\hline \multicolumn{5}{|l|}{ Locoregional failure, $n(\%)$} \\
\hline Primary & $10(7.2)$ & $16(11.6)$ & & \\
\hline Neck & $4(2.9)$ & $4(2.9)$ & & \\
\hline \multicolumn{5}{|l|}{ Distant metastases, $n(\%)$} \\
\hline Distant only & $10(7.2)$ & $9(6.5)$ & & \\
\hline Distant and locoregional & $2(1.4)$ & $3(2.2)$ & & \\
\hline
\end{tabular}

*Calculated using the Kaplan-Meier method. 
Table 4: Adverse events and treatment delays

\begin{tabular}{|c|c|c|c|}
\hline & $\begin{array}{l}\text { TPF+CCRT } \\
(n=138)\end{array}$ & $\begin{array}{c}\text { PF+CCRT } \\
(n=138)\end{array}$ & $P$-value* \\
\hline \multicolumn{4}{|c|}{ Adverse events during induction chemotherapy, $n(\%)$} \\
\hline \multicolumn{4}{|c|}{ Hematologic } \\
\hline Anemia (grade 3 or 4 ) & $3(2.2)$ & $3(2.2)$ & - \\
\hline Thrombocytopenia (grade 3 or 4 ) & $3(2.2)$ & $2(1.4)$ & - \\
\hline Neutropenia (grade 3 or 4 ) & $88(63.8)$ & $39(28.3)$ & $<0.001$ \\
\hline Febrile neutropenia & $14(10.1)$ & $4(2.9)$ & 0.015 \\
\hline \multicolumn{4}{|l|}{ Non-hematologic (grade 3 or 4 ) } \\
\hline Stomatitis (mucositis) & $3(2.2)$ & $6(4.3)$ & $0.501 \dagger$ \\
\hline Nausea & $12(8.7)$ & $18(13.0)$ & 0.246 \\
\hline Vomiting & $6(4.3)$ & $14(10.1)$ & 0.063 \\
\hline Diarrhea & $10(7.2)$ & $4(2.9)$ & 0.100 \\
\hline Fatigue & $15(10.9)$ & $10(7.2)$ & 0.294 \\
\hline Anorexia & $10(7.2)$ & $10(7.2)$ & - \\
\hline Liver dysfunction (grade 1 or 2 ) & $70(50.7)$ & $60(43.5)$ & 0.228 \\
\hline Kidney dysfunction (grade 1 or 2 ) & $3(2.2)$ & $11(8.0)$ & 0.028 \\
\hline \multicolumn{4}{|l|}{ Adverse events during chemoradiotherapy } \\
\hline \multicolumn{4}{|l|}{ Hematologic } \\
\hline Anemia (grade 3 or 4 ) & $34(24.6)$ & $17(12.3)$ & 0.008 \\
\hline Thrombocytopenia (grade 3 or 4 ) & $32(23.2)$ & $17(12.3)$ & 0.018 \\
\hline Neutropenia (grade 3 or 4 ) & $49(35.5)$ & $20(7.2)$ & $<0.001$ \\
\hline Febrile neutropenia & $5(3.6)$ & $2(1.4)$ & $0.447^{\dagger}$ \\
\hline \multicolumn{4}{|l|}{ Non-hematologic (grade 3 or 4 ) } \\
\hline Stomatitis (mucositis) & $30(21.7)$ & $35(25.4)$ & 0.478 \\
\hline Nausea & $11(8.0)$ & $12(8.7)$ & 0.828 \\
\hline Vomiting & $9(6.5)$ & $10(7.2)$ & 0.812 \\
\hline Diarrhea & $2(1.4)$ & $1(7.2)$ & - \\
\hline Fatigue & $20(14.5)$ & $18(13.0)$ & 0.727 \\
\hline Anorexia & $28(20.3)$ & $24(17.4)$ & 0.538 \\
\hline Dermatitis & $14(10.1)$ & $16(11.6)$ & 0.699 \\
\hline Oesophagitis, dysphagia or odynophagia & $5(3.6)$ & $7(5.1)$ & 0.555 \\
\hline Dry mouth & $7(5.1)$ & $8(5.8)$ & 0.791 \\
\hline Liver dysfunction (grade 1 or 2 ) & $62(44.9)$ & $22(15.9)$ & $<0.001$ \\
\hline Kidney dysfunction (grade 1 or 2 ) & $44(31.9)$ & $22(15.9)$ & 0.002 \\
\hline \multicolumn{4}{|l|}{ Cycles of concurrent chemotherapy } \\
\hline One & $26(18.8)$ & $27(19.6)$ & 0.879 \\
\hline Two & $112(81.2)$ & $111(80.4)$ & 0.879 \\
\hline
\end{tabular}

*Calculated using the $\chi^{2}$ test.

${ }^{\dagger}$ Calculated using Fisher's exact test. 
During chemoradiotherapy, grade 3 or 4 anemia occurred in $24.6 \%$ of patients in the TPF group and $12.3 \%$ of the PF group $(P=0.008)$, grade 3 or 4 thrombocytopenia occurred in $23.2 \%$ of the TPF group and $12.3 \%$ of the PF group $(P=0.018)$ and grade 3 or 4 neutropenia occurred in $35.5 \%$ of the TPF group and $7.2 \%$ of the PF group $(P<$ 0.001 ; Table 4$)$. There were higher frequencies of grade 1 or 2 liver dysfunction and kidney dysfunction in the TPF group than the PF group during chemoradiotherapy. In TPF group, Grade 3 or 4 neutropenia occurred in $57.6 \%$ of the male patients and $79.5 \%$ of the female patients while Febrile neutropenia occurred in $9.1 \%$ of the male patients and $12.8 \%$ of the female patients. Grade 3 or 4 Thrombocytopenia occurred in 1 male patients and 2 female patients while Grade 3 or 4 Anemia occurred in 2 male patients and 1 female patients. In PF group, Grade 3 or 4 neutropenia occurred in $22.4 \%$ of the male patients and $42.5 \%$ of the female patients while Febrile neutropenia occurred in $2.0 \%$ of the male patients and $5.0 \%$ of the female patients. Grade 3 or 4 Thrombocytopenia occurred in 2 male patients and 0 female patients while Grade 3 or 4 Anemia occurred in 0 male patients and 2 female patients. There were no significant differences in the frequencies of non-hematologic adverse events between groups during chemoradiotherapy. The percentage of patients who received two cycles of concurrent chemotherapy was similar between groups (Table 4).

\section{DISCUSSION}

Recently, a Bayesian network meta-analysis demonstrated the significant benefits of NACT + CCRT over CCRT in terms of distant metastasis rate (DMR). However, NACT + CCRT was associated with significantly poorer locoregional control; the higher toxicity of NACT frequently delayed CCRT, which may

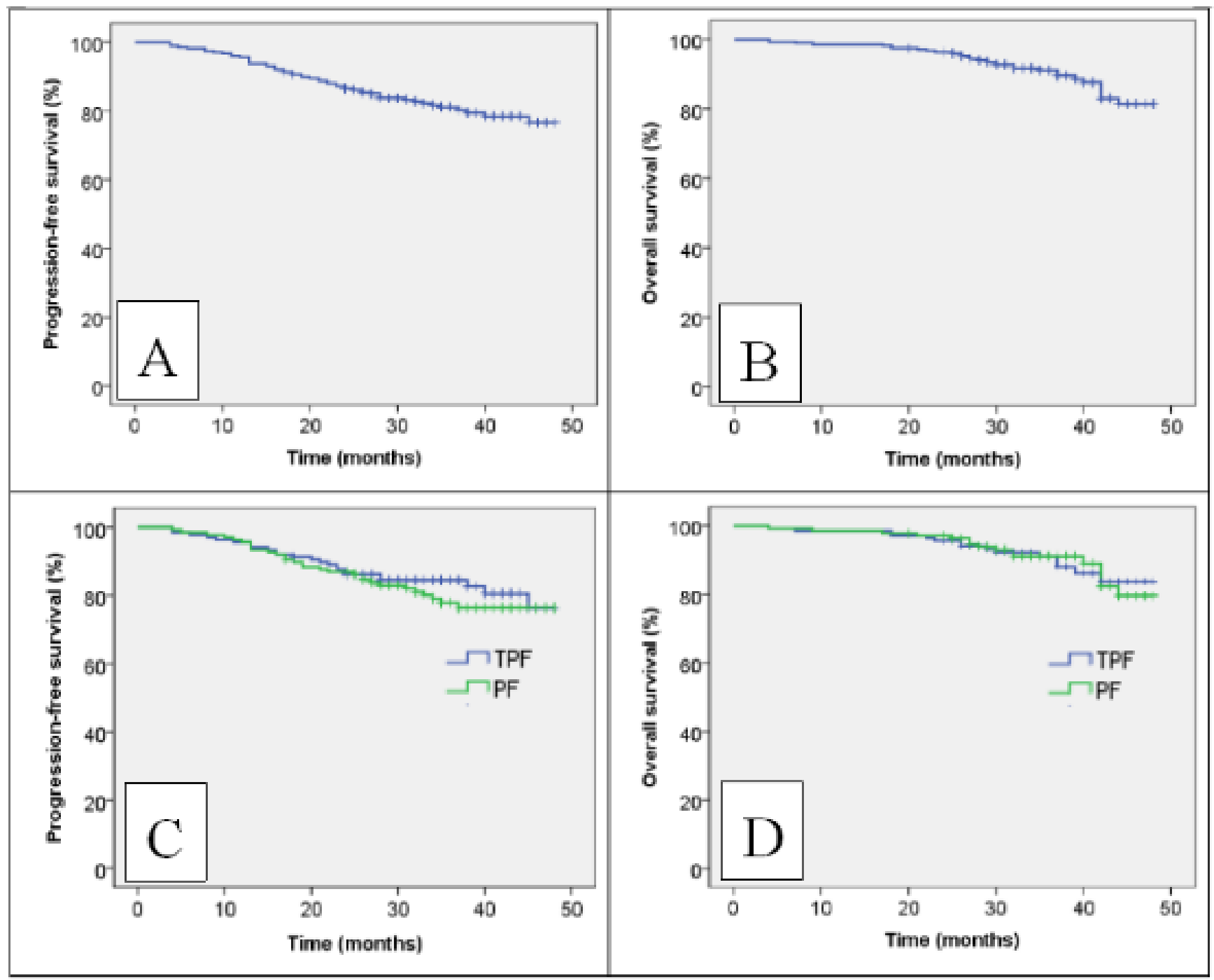

Figure 1: Kaplan-Meir progression-free survival (A) and overall survival curves (B) for all 276 patients and progressionfree survival (C) and overall survival curves (D) for the patients stratified by neoadjuvant chemotherapy regimen. 
allow tumor cell proliferation and offset locoregional control and survival benefits [22]. Therefore, selection of the optimal NACT strategy is crucial. In recurrent or metastatic NPC, PF resulted in a similar response rate as TPF (66-80\% vs. 72.5\%) [23-26] but a lower frequency of grade IV myelosuppression (3\% vs. 22.2\%) [25, 26]. In locally-advanced NPC, PF produced a similar response rate after induction chemotherapy as TPF ( $85 \%$ vs. $89 \%)$ $[27,28]$. Therefore, we speculated PF and TPF would have a similar efficacy, but patients with locoregionallyadvanced NPC would have better tolerance and compliance to PF than TPF.

Hui et al. [29] observed a significant improvement in OS when TP was added to concurrent cisplatin and conventional radiation $(94.1 \%$ vs. $67.7 \%, P=0.012)$. Ekenel et al. ${ }^{[30]}$ reported estimated 3 year PFS and OS rates of $84.7 \%$ and $94.9 \%$ for 59 patients with NPC who received three cycles of induction TP regimen followed by combined cisplatin-based CCRT. However, these studies assessed low numbers of patients with stage IV NPC (22\%-44.1\%) and employed conventional radiation. In 2013, a study at the Shanghai Cancer Center confirmed these encouraging results and suggested TPF induction chemotherapy followed by CCRT using current standard radiation techniques, 3-dimensional conformal radiation therapy (3D-CRT) or IMRT led to superior outcomes: Lin Kong et al. [31] reported 3-year PFS, distant metastasisfree survival, and local PFS rates of $78.2 \%, 90.5 \%$, and 93.9\% respectively for 52 patients with stage III NPC and $85.1 \%, 88 \%$ and $100 \%$ respectively for 64 patients with stage IVA/IVB NPC who received TPF $\left(75 \mathrm{mg} / \mathrm{m}^{2}\right.$ docetaxel, $75 \mathrm{mg} / \mathrm{m}^{2}$ cisplatin, $2500 \mathrm{mg} / \mathrm{m}^{2} 5$-fluoruracil every 3 weeks for three cycles) followed by cisplatin 40 $\mathrm{mg} / \mathrm{m}^{2}$ per week concurrently with $3 \mathrm{D}$-CRT or IMRT. The PFS and OS rates for TPF in this study are similar to those reported by Lin Kong et al. [31] (84.5\% vs. 78.2$85.1 \%$ and $91.1 \%$ vs. $90.2-94.8 \%$ ). However, in this trial, TPF provided a non-significant PFS benefit compared to PF $(84.5 \%$ vs. $77.9 \%, P=0.380)$. Moreover, the rates of locoregional failure and distant metastases did not differ significantly for PF and TPF.

TPF induces high rates of grade 3 or 4 neutropenia (56-76.9\%) in unresectable head and neck cancer [19, 20]. When G-CSF support was provided, a lower incidence of grade 3 or 4 neutropenia was achieved (55.2\%). [31] In this study, grade 3 or 4 neutropenia occurred in $63.8 \%$ of the TPF group and only $28.3 \%$ of the PF group $(P<$ $0.001)$. Although all patients completed three planned courses of TPF in this study, the higher incidences of grade 3 or 4 neutropenia and diarrhea led to significantly more treatment delays and dose modifications in this arm. In contrast, only $88.8 \%$ of patients completed all three courses of TPF in the study by Kong et al. [31]. In this trial, TPF led to a lower frequency of kidney dysfunction than PF, which can be attributed to the lower dose of cisplatin. Except for a non-significant difference in vomiting, which was more frequent for PF, there was no significant difference in non-hematologic adverse events between groups during induction chemotherapy. Although there were higher frequencies of myelotoxicity, liver dysfunction and kidney dysfunction during chemoradiotherapy after TPF than PF, similar numbers of patients in both groups received two cycles of concurrent chemotherapy ( $81.2 \%$ vs. $80.4 \%, P=0.879)$. Kong et al. [31] reported only $66.4 \%$ of patients completed at least five courses of concurrent chemotherapy after TPF.

The current sample size has not met the requirements of the power calculation; therefore, caution must be taken when reviewing these conclusions. As discussed above, grade 3 or 4 neutropenia and treatment delays occurred in $63.8 \%$ and $33.3 \%$ of the TPF group, respectively. Therefore, after these first 138 patients were included, all patients subsequently allocated to the TPF group received three cycles of modified induction chemotherapy $\left(60 \mathrm{mg} / \mathrm{m}^{2}\right.$ docetaxel, $75 \mathrm{mg} / \mathrm{m}^{2}$ cisplatin, $2400 \mathrm{mg} / \mathrm{m}^{2} 5$-flurouracil). In 2013, the Shanghai Cancer Center reported good tolerance and compliance rates for three cycles of modified induction docetaxel $\left(60 \mathrm{mg} / \mathrm{m}^{2}\right)$, cisplatin $\left(75 \mathrm{mg} / \mathrm{m}^{2}\right)$ and 5-flurouracil $\left(1500 \mathrm{mg} / \mathrm{m}^{2}\right)$ : $23.3 \%(14 / 60)$ of patients experienced grade 3 or grade 4 neutropenia and only $1.7 \%(1 / 60)$ developed febrile neutropenia [28].

This interim analysis indicates that PF induction chemotherapy has substantially better tolerance and compliance rates among patients with locally-advanced NPC than TPF induction chemotherapy; however, while the TPF arm achieved better PFS than the PF arm, this difference was not statistically significant. Our result needs supportive in vitro and vito experiments. We will start the vitro and vito experiments in future and report it in the long-term results of our randomised phase 3 trial. Further investigation is warranted.

\section{Novelty and Impact}

In this study, we aim to compare the progressionfree survival (PFS) rates and side effects of induction chemotherapy based on TPF versus PF in patients with locoregionally-advanced nasopharyngeal carcinoma who received subsequent chemoradiotherapy. Our findings suggest that PF induction chemotherapy has substantially better tolerance and compliance rates than TPF induction chemotherapy. A PFS benefit was observed for TPF compared to PF, though this difference was not statistically significant $(84.5 \%$ vs. $77.9 \%, P=0.380)$.

\section{Abbreviations}

progression-free survival (PFS), docetaxel, cisplatin and fluorouracil (TPF), cisplatin and fluorouracil (PF), nasopharyngeal cancer (NPC), overall survival (OS), 
concurrent chemoradiotherapy (CCRT), neoadjuvant chemotherapy (NACT), squamous cell carcinoma of the head and neck (SCCHN), American Joint Committee on Cancer (AJCC), intensity modulated radiation therapy (IMRT), Gross tumor volume (GTV), Clinical target volume (CTV), distant metastasis rate (DMR), 3-dimensional conformal radiation therapy (3D-CRT).

\section{ACKNOWLEDGMENTS}

This work was supported by the National Natural Science Foundation of China [Grant No. 81372437]; the China International Medical Foundation [No. CIMFF-H001-043]; and the Excellent Talents Project of Zhejiang Cancer Hospital, P. R. China [No. 2013 to T.J.]. We thank Dr. Shuang Huang, Dr. Chan-juan Tao, Dr. Yong-hong Hua, Dr. Qiao-ying Hu, Dr. Yong-feng Piao, Dr. Fu-jun $\mathrm{Hu}$, and Dr. Bin Li for for collecting the data.

\section{CONFLICTS OF INTEREST}

The authors declare that they have no conflict of interest

\section{REFERENCES}

1. Heng DM, Wee J, Fong KW, Lian LG, Sethi VK, Chua ET, Yang TL, Khoo Tan HS, Lee KS, Lee KM, Tan T, Chua EJ. Prognostic factors in 677 patients in Singapore with nondisseminated nasopharyngeal carcinoma. Cancer. 1999; 86: 1912-1920.

2. Ma J, Mai HQ, Hong MH, Cui NJ, Lu TX, Lu LX, Mo HY, Min HQ. Is the 1997 AJCC staging system for nasopharyngeal carcinoma prognostically useful for Chinese patient populations?. Int J Radiat Oncol Biol Phys. 2001; 50: 1181-1189.

3. Yeh SA, Tang Y, Lui CC, Huang YJ, Huang EY. Treatment outcomes and late complications of 849 patients with nasopharyngeal carcinoma treated with radiotherapy alone. Int J Radiat Oncol Biol Phys. 2005; 62: 672-679.

4. Au JS, Law CK, Foo W, Lau WH. In-depth evaluation of the AJCC/UICC 1997 staging system of nasopharyngeal carcinoma: prognostic homogeneity and proposed refinements. Int J Radiat Oncol Biol Phys. 2003; 56: 413426.

5. Chua DT, Sham JS, Wei WI, Ho WK, Au GK. The predictive value of the 1997 American Joint Committee on Cancer stage classification in determining failure patterns in nasopharyngeal carcinoma. Cancer. 2001; 92: 2845-2855.

6. $\quad$ Leung TW, Tung SY, Sze WK, Wong FC, Yuen KK, Lui CM, Lo SH, Ng TY, O SK. Treatment results of 1070 patients with nasopharyngeal carcinoma: an analysis of survival and failure patterns. Head Neck. 2005; 27: 555565.

7. Lee AW, Sze WM, Au JS, Leung SF, Leung TW, Chua
DT, Zee BC, Law SC, Teo PM, Tung SY, Kwong DL, Lau WH. Treatment results for nasopharyngeal carcinoma in the modern era: the Hong Kong experience. Int J Radiat Oncol Biol Phys. 2005; 61: 1107-1116.

8. Lai SZ, Li WF, Chen L, Luo W, Chen YY, Liu LZ, Sun Y, Lin AH, Liu MZ, Ma J. How does intensitymodulated radiotherapy versus conventional twodimensional radiotherapy influence the treatment results in nasopharyngeal carcinoma patients?. Int J Radiat Oncol Biol Phys. 2011; 80: 661-668.

9. Lin JC, Jan JS, Hsu CY, Liang WM, Jiang RS, Wang WY. Phase III study of concurrent chemoradiotherapy versus radiotherapy alone for advanced nasopharyngeal carcinoma: positive effect on overall and progression-free survival. J Clin Oncol. 2003; 21: 631-637.

10. Chan AT, Teo PM, Ngan RK, Leung TW, Lau WH, Zee B, Leung SF, Cheung FY, Yeo W, Yiu HH, Yu KH, Chiu KW, Chan DT, et al. Concurrent chemotherapy-radiotherapy compared with radiotherapy alone in locoregionally advanced nasopharyngeal carcinoma: progression-free survival analysis of a phase III randomized trial. J Clin Oncol. 2002; 20: 2038-2044.

11. Langendijk JA1 Leemans CR, Buter J, Berkhof J, Slotman BJ. The additional value of chemotherapy to radiotherapy in locally advanced nasopharyngeal carcinoma: a metaanalysis of the published literature. J Clin Oncol. 2004; 22: 4604-4612.

12. Baujat B, Audry H, Bourhis J, Chan AT, Onat H, Chua DT, Kwong DL, Al-Sarraf M, Chi KH, Hareyama M, Leung SF, Thephamongkhol K, Pignon JP; MAC-NPC Collaborative Group. Chemotherapy in locally advanced nasopharyngeal carcinoma: an individual patient data meta-analysis of eight randomized trials and 1753 patients. Int J Radiat Oncol Biol Phys. 2006; 64: 47-56.

13. Wei WI, Sham JS. Nasopharyngeal carcinoma. Lancet. 2005; 365: 2041-2054.

14. Rossi A, Molinari R, Boracchi P, Del Vecchio M, Marubini E, Nava M, Morandi L, Zucali R, Pilotti S, Grandi C. Adjuvant chemotherapy with vincristine, cyclophosphamide, and doxorubicin after radiotherapy in local-regional nasopharyngeal cancer: results of a 4-year multicenter randomized study. J Clin Oncol. 1988; 6: 14011410 .

15. Chan AT, Teo PM, Leung TW, Leung SF, Lee WY, Yeo $\mathrm{W}$, Choi PH, Johnson PJ. A prospective randomized study of chemotherapy adjunctive to definitive radiotherapy in advanced nasopharyngeal carcinoma. Int J Radiat Oncol Biol Phys. 1995; 33: 569-577.

16. Al-Sarraf M, LeBlanc M, Giri PG, Fu KK, Cooper J, Vuong T, Forastiere AA, Adams G, Sakr WA, Schuller DE, Ensley JF. Chemoradiotherapy versus radiotherapy in patients with advanced nasopharyngeal cancer: phase III randomized Intergroup study 0099. J Clin Oncol. 1998; 16: 310-1317.

17. Chi KH, Chang YC, Guo WY, Leung MJ, Shiau CY, Chen SY, Wang LW, Lai YL, Hsu MM, Lian SL, Chang CH, 
Liu TW, Chin YH, et al. A phase III study of adjuvant chemotherapy in advanced nasopharyngeal carcinoma patients. Int J Radiat Oncol Biol Phys. 2002; 52: 12381244.

18. OuYang PY, Xie C, Mao YP, Zhang Y, Liang XX, Su Z, Liu Q, Xie FY. Significant efficacies of neoadjuvant and adjuvant chemotherapy for nasopharyngeal carcinoma by meta-analysis of published literature-based randomized, controlled trials. Ann Oncol. 2013; 24: 2136-2146.

19. Vermorken JB, Remenar E, van Herpen C, Gorlia T, Mesia R, Degardin M, Stewart JS, Jelic S, Betka J, Preiss JH, van den Weyngaert D, Awada A, Cupissol D, et al. Cisplatin, fluorouracil, and docetaxel in unresectable head and neck cancer. N Engl J Med. 2007; 357: 1695-1704.

20. Posner MR, Hershock DM, Blajman CR, Mickiewicz E, Winquist E, Gorbounova V, Tjulandin S, Shin DM, Cullen K, Ervin TJ, Murphy BA, Raez LE, Cohen RB, et al. Cisplatin and fluorouracil alone or with docetaxel in head and neck cancer. N Engl J Med. 2007; 357: 1705-1715.

21. Liu YJ, Zhu GP, Guan XY. Comparison of the NCI-CTCAE version 4.0 and version 3.0 in assessing chemoradiationinduced oral mucositis for locally advanced nasopharyngeal carcinoma. Oral Oncol. 2012;48: 554-559.

22. Chen YP, Guo R, Liu N, Liu X, Mao YP, Tang LL, Zhou GQ, Lin AH, Sun Y, Ma J. Efficacy of the Additional Neoadjuvant Chemotherapy to Concurrent Chemoradiotherapy for Patients with Locoregionally Advanced Nasopharyngeal Carcinoma: a Bayesian Network Meta-analysis of Randomized Controlled Trials. J Cancer. 2015; 6: 883-892.

23. Wang TL, Tan YO. Cisplatin and 5-fluorouracil continuous infusion for metastatic nasopharyngeal carcinoma. Ann Acad Med Singapore. 1991; 20: 601-603.

24. Au E, Ang PT. A phase II trial of 5-fluorouracil and cisplatinum in recurrent or metastatic nasopharyngeal carcinoma. Ann Oncol. 1994; 5: 87-89.
25. hi KH, Chan WK, Cooper DL, Yen SH, Lin CZ, Chen KY. A phase II study of outpatient chemotherapy with cisplatin, 5-fluorouracil, and leucovorin in nasopharyngeal carcinoma. Cancer. 1994; 73: 247-252.

26. Huang HQ, Cai QQ, Lin XB, Wang AL, Bu Q, Hu XH, Pan ZH, Li YH, Shuang YR, Guan ZZ. [Preliminary result of multi-center clinical trial on the docetaxel, 5-Fu and DDP in the treatment of advanced, recurrent or metastatic nasopharyngeal carcinoma]. Zhonghua Zhong Liu Za Zhi. 2008; 30: 314-316.

27. Xie FY, Qi SN, Hu WH, Zou GR, Peng M, Li JS. [Comparison of efficacy of docetaxel combined cisplatin (TP regimen) and cisplatin combined 5-fluorouracil (PF regimen) on locally advanced nasopharyngeal carcinoma]. Ai Zheng. 2007; 26: 880-884.

28. Du C, Ying H, Zhou J, Hu C, Zhang Y. Experience with combination of docetaxel, cisplatin plus 5-fluorouracil chemotherapy, and intensity-modulated radiotherapy for locoregionally advanced nasopharyngeal carcinoma. Int J Clin Oncol. 2013; 18: 64-471.

29. Hui EP, Ma BB, Leung SF, King AD, Mo F, Kam MK, Yu BK, Chiu SK, Kwan WH, Ho R, Chan I, Ahuja AT, Zee BC, Chan AT. Randomized phase II trial of concurrent cisplatinradiotherapy with or without neoadjuvant docetaxel and cisplatin in advanced nasopharyngeal carcinoma. J Clin Oncol. 2009; 27: 242-249.

30. Ekenel M, Keskin S, Basaran M, Ozdemir C, Meral R, Altun M, Aslan I, Bavbek SE. Induction chemotherapy with docetaxel and cisplatin is highly effective for locally advanced nasopharyngeal carcinoma. Oral Oncol. 2011; 47: 660-664.

31. Kong L, Hu C, Niu X, Zhang Y, Guo Y, Tham IW, Lu JJ. Neoadjuvant chemotherapy followed by concurrent chemoradiation for locoregionally advanced nasopharyngeal carcinoma: interim results from 2 prospective phase 2 clinical trials. Cancer. 2013; 119: 4111-4118. 